\title{
ON THE DIMINUTION
}

\section{of THE \\ CHLORIDES IN THE URINE, \\ OR THEIR}

ABSENCE FROM THAT FLUID IN CASES OF PNEUMONIA;

AND ON THE

CHEMICAL COMPOSITION OF THE SPUTA IN THAT DISEASE.

BX

LIONEL SMITH BEALE, M.B., LONDON.

COMMUNICATED BY

D R. TO D D, F.R.S.

PHYSICIAN TO KING'S COLLEGE HOSPITAL.

Received April 13th.-Read June 8th, 1852.

IN August, 1850, Dr. Redtenbacher published some observations on the absence of chloride of sodium from the urine in cases of pneumonia. ${ }^{1}$ This physician noticed that the quantity of chloride gradually diminished until the period of hepatization had occurred, when no traces whatever of the presence of the salt could be detected in the urine, but the chloride again made its appearance as the resolution of the inflammation progressed.

Since the publication of this interesting observation, so far as I am aware, no farther investigations on this subject, at least in this country, have been instituted, nor has any explanation of the fact been as yet offered.

A diminution in the quantity of chloride of sodium in the urine of various inflammatory diseases was remarked by Franz Simon; and all observers agree that in inflammations generally, the urine contains a greater relative amount of

' Zeitschrift der k. k. Gesellschaft der Aertze zu Wien. August, 1850. 
organic constituents than in health, while, on the other hand, the inorganic salts suffer a remarkable diminution.

This decrease in quantity of the inorganic salts is, doubtless, in part due to the altered diet taken'by patients suffering from acute inflammatory diseases; but it will presently be shown that such an explanation alone will not suffice to account for the facts observed. In inflammatory attacks generally, although the chlorides may suffer diminution in quantity, or are altogether absent, this is not constantly the case, neither does the salt disappear at any particular period of the inflammation; but it has been shown by the observations of Dr. Redtenbacher on eighty cases of pneumonia, that in this disease the chlorides are invariably absent, and that the salt disappears from the urine at the precise period at which hepatization occurs in the lung.

Soon after the appearance of Dr. Redtenbacher's paper, I commenced a series of observations on the urine and other secretions in cases of pneumonia, with the view of making out, if possible, the channel through which the chloride of sodium was eliminated from the system in this disease, or the locality in which it was stored up during the persistence of the hepatization of the lung, and also with the hope of being able to trace the connection between the absence of the salt from the urine and the occurrence of hepatization.

My observations were made as opportunities occurred, on cases which were admitted into King's College Hospital ; and for the advantage of prosecuting these inquiries, I am indebted to the kindness of the physicians of the hospital.

The cases were taken indiscriminately as they came into the hospital, and, consequently, both mild and severe cases have been the subject of observation. The detail of every examination of the urine, and all other circumstances connected with the subject that have fallen under my notice, have been reported, and the results which I have obtained may perhaps be found not unworthy of the attention of the Society.

In order to detect the presence of the chloride in the urine, Dr. Redtenbacher added a few drops of a solution of nitrate of silver to a portion of the urine acidulated 
with nitric acid, and by the character of the precipitate so produced, he was enabled to judge roughly as to the excess or deficiency of the chlorides. Being anxious to obtain quantitative results in my analyses, I pursued a different method of investigation. My experiments were made simply with reference to the amount of fixed chloride, hence it became necessary to avoid the estimation of any volatile chlorine salt with the chloride of sodium, for it has been shown that a large quantity of hydrochlorate of ammonia often exists in urine; and if this salt were present in a specimen of urine which was tested as above described, with nitrate of silver and nitric acid, an abundant precipitate of chloride of silver would be thrown down, and the erroneous inference, that the urine contained an abundant quantity of chloride of sodium, might be drawn, although not a trace of it was present. Heller met with a case of pneumonia of the right lung occurring in a boy fourteen years of age, whose urine contained a large amount of hydrochlorate of ammonia, although only a mere trace of chloride of sodium could be detected. ${ }^{1}$

The following method was followed in the accompanying analyses. After ascertaining the reaction and specific gravity of the urine, 500 or 1000 grains were evaporated to dryness over a water bath, and when the dry residue ceased to lose weight by further drying, at a temperature of about $200^{\circ}$ in a small hot water oven, its weight was noted, and being subtracted from the weight of the urine, the quantity of water in the portion of urine operated upon was obtained. A weighed portion of the solid residue was incinerated, and exposed to a dull red heat until thoroughly decarbonised, when its weight was taken, and from the result, the amount of salts present in the solid matter of 1000 grains of urine was easily calculated. The fixed salts were dissolved in a little distilled water, and acidulated by the addition of a few drops of nitric acid; a solution of nitrate of silver being then added, the presence or absence of fixed chloride was at once

' Simon's 'Animal Chemistry;' Sydenham Society's edition, translated by Day, vol. ii, p. 218. 
determined. If a precipitate was produced, it was thrown upon a filter, washed, dried, ignited in a porcelain crucible, and weighed; the quantity in 1000 grains of urine was then calculated as before, and the proportion of chloride of sodium corresponding to the amount of chloride of silver ascertained. Thus, the quantities of solid matter, fixed salts, and chloride of sodium present in 1000 grains of urine were determined.

In all my analyses in which the amount of chloride was estimated, a similar process was followed; and in this way the quantity of chloride existing in the sputa, blood, and urine, at the same period of the disease, was ascertained in one of the cases recorded.

In all chemico-pathological investigations, it is a point of the utmost importance that the case forming the subject of the inquiry should be a well-marked instance of the particular morbid condition under consideration, for upon this fact alone can the value of the inferences drawn from the facts observed depend.

Frequently the diagnosis of a particular case has not with certainty been ascertained, or the patient may have been labouring under two or more morbid affections at the same time; and in consequence of this not having been discovered, or no record kept, all the labour of the chemist is unproductive of any useful result. At the same time care should be taken that the pathological observations of the chemist are not simply dependant upon the treatment pursued by the physician.

Although a recital of the cases of pneumonia, on which my observations were made, will necessarily prolong this paper to a length which the importance of the subject is scarcely sufficient to demand, I felt that, without a short history of the cases, and of the treatment followed in each, the statements brought forwards as facts, observed in certain cases of pneumonia, could not be relied on with that degree of confidence which can alone render original inquiry of interest to others. I have, therefore, appended a short history of each case, with a general outline of the treatment pursued. In most instances the abstract was prepared 
from the notes kept by the clinical clerks of the physician, under whose care the patient was placed.

In order that the results obtained in each analysis might be compared with each other, I have calculated, from the figures representing the quantity of each constituent existing in 1000 grains of the fluid, the quantity which would be present in 100 grains of solid matter,-by which mode of representing the results of analysis much ambiguity is prevented, and the apparent dissimilarity in composition of fluids, taken at different periods of time and from different cases, arising merely from a varying quantity of water, is avoided. For the conflicting results obtained by chemists in reference to the composition of particular animal fluids may often be referred to the presence of a different quantity of water, while the relation of each constituent to the others remains the same, as shown by a simple calculation; or, on the other hand, striking variations in the relative proportions may exist, and may entirely escape notice, if this reduction be neglected.

Before entering into the details which I have collected with reference to the subject, I will premise the following remarks. A deficiency of chloride of sodium, or its total absence from the urine, is not by any means peculiar to cases of pneumonia, nor even to acute inflammatory disease generally. An absence of the salt has been noticed in various conditions by several observers; and more than one case in which its absence could not be traced to any such cause has fallen under my own notice. It will probably be found that the presence of this salt in the urine merely depends upon a quantity of it being taken with the food greater than is required for the wants of the system, (in which case chloride of sodium would hardly be enumerated as one of the necessary constituents of healthy urine;) but in the present state of knowledge we are hardly justified in drawing such an inference; hence, throughout this paper, I have considered that healthy urine contains a certain quantity of this salt, (about 3.5 per 1000 parts, or five per cent. in the solid matter,) although, in different analyses of the 
normal secretion, we find the quantity of the salt subject to great variations.

The absence of chloride of sodium from the urine, I believe, indicates that there is a deficiency, or at least that there is no excess, of the salt in the blood; and therefore, taken alone, it must be regarded as an interesting fact in the pathology of pneumonia, for it appears to be constantly absent in this disease, although it is also occasionally absent from the urine of other affections; but, when its absence from the urine in pneumonia is considered in conjunction with the existence of a considerable excess of the salt in other secretions, or in the inflammatory products, it may be looked upon as one link of a chain of phenomena which, when more fully investigated, appears likely to shed a new light upon the hidden processes of pathological metamorphoses.

Casr r.'-Samuel Trevitt, at. 24, a plasterer by trade. Eight years ago he contracted syphilis, and has never been in good health since this period. He had suffered from sore throat; and about six months before his admission into the hospital, an abscess formed on the left side of the forehead, and soon broke, leaving a sore which has not since healed. Three months since a portion of the frontal bone, about the size of a fourpenny piece, became exposed at the bottom of the wound, and still continues bare; it was quite black, and did not manifest the slightest tendency to separate.

The patient had been troubled with slight cough for a fortnight before the symptoms of pneumonia manifested themselves.

First day of the disease.-On January the 4th the man was seized with three or four sharp rigors, followed by pain in the chest and loss of appetite. At the same time his cough much increased in severity. He was admitted into the hospital on January the 6th, under the care of Dr. Budd.

Third day of the disease: January 6th.-The patient complained of having been attacked with severe rigors, 1 From the notes of Mr. Hoar. 
coming on three or four times a day since the 4th. He also suffered from pain in the loins, and great difficulty of breathing. There was fixed pain in the front of the sternum, and a sharp catching pain came on frequently in the left side of the chest. The patient said that he felt excessively weak. The tongue was covered with a thick white fur, the skin was hot and dry, and the lips were parched. The right side of the chest, more particularly at the lower part, was observed to expand more than the left during the movements of respiration. In front, dulness on percussion was present from two inches below the left mamma to the base of the lung; and behind, it existed over the space below the spine of the left scapula. Bronchial breathing and bron. chophony were audible over the lower angle of the scapula. Expectoration viscid, frothy, and slightly rusty. Pulse 144, small and weak; respiration, 52.

The patient was put upon milk diet and beef tea. Turpentine stupes were applied to the chest, and he was ordered to take half a drachm of antimonial wine every four hours.

Fourth day of the disease: January 7th.-Bronchial breathing and bronchophony more distinct, and heard over the infra-spinal region. The dulness confined to the situation of the lower lobe of the left lung. Pain in the side better. Purged six times since last night. Has vomited in the night, but by this time the nausea had left him.

The same quantity of antimonial wine was ordered to be taken every six hours, and the turpentine stupes to be repeated twice in the day. Pulse 116 ; respiration 28.

The urine was high coloured, of acid reaction, and of specific gravity 1017. It contained a little albumen.

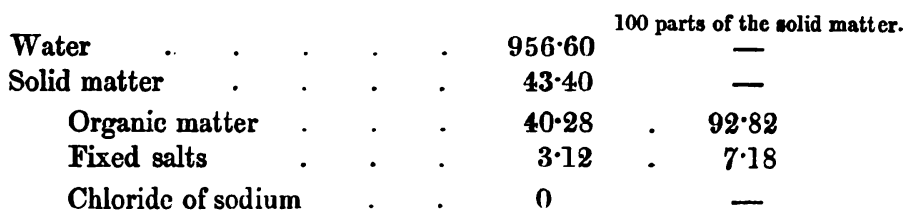

Fifth day of the disease: January 8th.-The patient had been purged three times since the last report. The tongue 
was cleaner, and he did not suffer from any pain. Bronchial breathing could only be heard upon a deep inspiration. Returning crepitation was audible in the lower part of the left lung. Fxpectoration still rusty. Pulse 88; respiration 28.

Fifteen minims of antimonial wine were ordered to be taken every six hours.

The urine was of the natural colour, of a slightly acid reaction, and specific gravity 1013; it still contained albumen.

$\begin{array}{llllllr}\text { Water } & . & . & . & . & . & \mathbf{9 5 7} 40 \\ \text { Solid matter } & . & . & . & . & . & \mathbf{4 2 . 6 0}\end{array}$

Chloride of sodium . . . . . traces.

Sixth day of the disease: January 9th.-Crepitation increased. Bronchial breathing still audible upon deep inspiration, about the spine of the scapula. Pulse 80; respiration 28.

The urine was pale in colour, of acid reaction, and its specific gravity was 1016 ; albumen was still present.

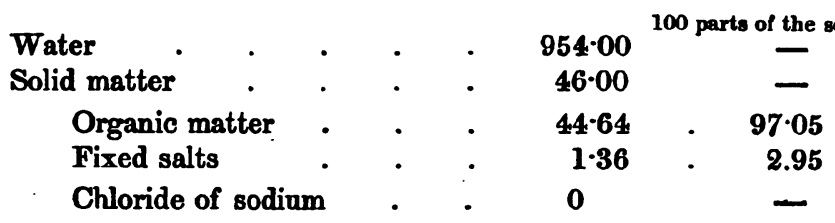

Eighth day of the disease: January 11th.-Tongue clean. Crepitation much increased. Bronchial breathing audible. Dulness still remains. Passed about three pints of urine in the twenty-four hours. Pulse 84; respiration 24.

Tenth day of the disease: January 13th.-The urine was acid; of specific gravity 1022. The presence of albumen was no longer detected.

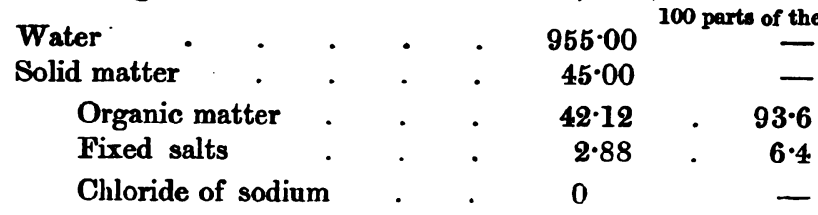

On January 15 th the antimony was discontinued, and an 
ounce of the solution of citrate of ammonia, which was ordered to be taken three times a day, was substituted for it.

On January 25th it was noted that the expectoration had almost entirely ceased. The tongue was clean. Dulness, however, was still present over the lower lobe of the left lung, and bronchial breathing was just audible over the infra spinal fossa, when the patient took a deep breath. Pulse 64.

The urine was pale, acid, and of specific gravity 1016 ; it did not contain albumen.

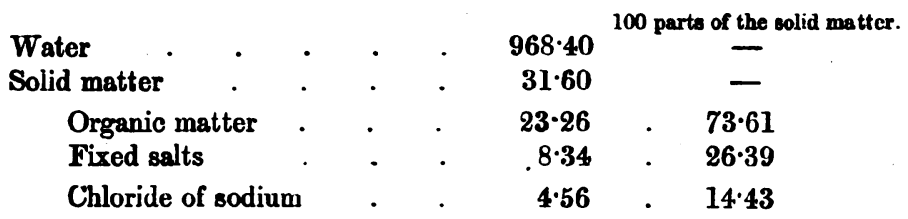

From this period the patient gradually improved, and he was discharged well on February the 8th. The syphilitic sore on the forehead had not altered in appearance since his admission.

In comparing the analysis of the urine in the present case, it may be remarked that on the fourth day of the disease, when the symptoms of the affection were well developed, there was a considerable decrease in the amount of fixed salts as compared with healthy urine, and that the saline constituents generally had suffered a great diminution relatively to the solid matter of the urine. On the fifth day of the disease traces of chloride of sodium were detected; this, however, may have been merely accidental.

On the sixth day of the disease a further diminution in the quantity of saline matter was observed, although the case was progressing very favorably and the signs of resolution were well marked. The decrease may perhaps be explained by the purging, from which the patient suffered on the previous day. On the tenth day the amount of salts had again increased, but still no chloride of sodium could be detected.

On the twenty-second day from the commencement of the symptoms, the urine was againe examined, and the 
relative proportion of salts was found to have slightly exceeded the healthy standard. At the same time there existed an amount of chloride of sodium somewhat greater than that found in healthy urine; but in a state of health the quantity of this salt is subject to great variations. In the present instance there were found 14.43 to 100 of solid matter, the amount in health being about $5 \cdot 4$, although in an analysis of healthy urine by Franz Simon, there existed as much as $14 \cdot 13$, corresponding to 100 of solid matter.

From the examination of the urine in this case, the following facts were observed :

1. A considerable relative diminution of the quantity of the salts generally, until the patient progressed towards convalescence, when the amount again increased, until, on the twenty-second day, the quantity was found to exceed that present in health.

2. A total absence of chloride of sodium from the urine, (with the exception of one day, on which traces were found,) until convalescence was established.

3. The presence of albumen in the urine from the fourth day of the disease to the sixth inclusive, (during which period the pneumonia was at its height.) On the tenth day albumen could not be detected in the urine.

Case II. ${ }^{-}$-Edward Mills, æt. 28, a man of middle stature, having a fair complexion and red hair, was admitted into the hospital on February the 5th, 1851, under the care of Dr. Todd. The patient was a railway porter, and had usually been in the enjoyment of excellent health. On February the $3 \mathrm{~d}$ he was attacked with shivering, shortness of breath, accompanied with cough, and a sharp cutting pain in the left side. In a short time these symptoms were succeeded by excessive thirst, loss of appetite, and the expectoration of viscid rusty-coloured mucus.

Third day of the disease.-On February the 5th the following physical signs were observed: dulness on percussion existed over the lower half of the left side of the chest behind, extending quite to the base of the lung, and reaching 
laterally to a line drawn downwards from a short distance below the axilla. Bronchial breathing and bronchophony were heard over this part of the chest, and the voice was rather agophonic in character. In other situations the breathing was healthy. The sputa were abundant, very viscid, and highly rusty. Urine scanty and high-coloured. Pulse 96. Respiration 36.

He was ordered to take an ounce of the liquor ammonix citratis every four hours, and turpentine stupes were applied to the left side of the chest. He was put upon milk diet with beef-tea.

Fourth day of the disease. - On February the 6th the urine had an acid reaction, and contained a deposit of lithate of ammonia with many rhomboidal crystals of lithic acid. A specimen of this urine contained,-

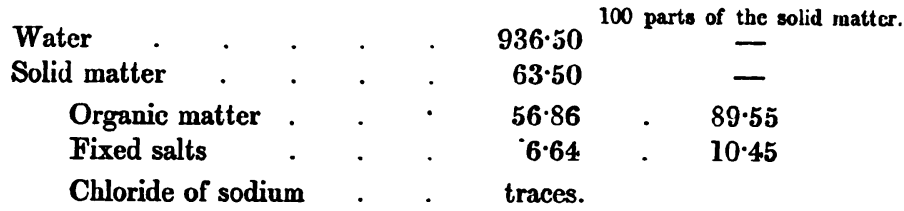

The ash was dissolved in water, acidulated with nitric acid. The addition to this solution of a few drops of a solution of nitrate of silver produced a slight turbidity.

Fifth day of the disease.-On the 7 th there was no great alteration in the character of the symptoms, except in the commencement of large crepitation at the base of the left lung. The pulse was 90, and the respiration 36. An herpetic eruption had appeared on the lips. He was ordered to take the citrate of ammonia every three hours, and to continue the stupes night and morning.

He still complained of pain in the left side. The deposit which subsided from the urine consisted chiefly of lithate of ammonia, with a few transparent casts, and a few lithic acid crystals. Its reaction was acid, and its specific gravity 1025.

The ash, obtained by incinerating and decarbonising a portion of the solid residue of evaporation, contained only a trace of chloride. 
Sixth day of the disease. - On the 8th, in consequence of the continuance of severe pain in the side, Dr. Todd ordered the application of ten leeches, which was followed by immediate relief. The sputa were less viscid, but still rusty. Pulse 80. Respiration 40.

The urine exhibited an acid reaction, and had a specific gravity of 1025. The deposit consisted of lithate of am. monia, with a little lithic acid. The ash was tested as before for chloride, but not a trace could be detected.

On the 9th the respirations had fallen to 30 , and bronchial breathing was entirely replaced by crepitation.

Eighth day of the disease.-On February the 10th (the fifth day after admission) the following was the condition of the patient :-His skin was moist. The rusty character of the sputa had entirely disappeared. Upon listening carefully to his chest a little fine crepitation was still heard over one spot upon a deep inspiration, and there was slight resonance of voice below the angle of the scapula. The cough was less frequent, and the tongue was clean.

From this period the patient gradually progressed, and left the hospital quite well on February the 20th, having been fifteen days under treatment.

The urine continued to deposit lithate of ammonia and lithic acid during the whole period of the disease. On the 13th it was found to be acid, and its specific gravity was 1030. It contained an abundant deposit of lithate of ammonia, and its surface was covered with an iridescent pellicle. The urine was not farther examined.

In this case small quantities of chloride of sodium were deterted in the urine up to the fifth day of the disease, when resolution of the inflammation had commenced: on the following day, however, not a trace of the salt could be discovered. Lithate of ammonia was present in the urine throughout the disease, and the specific gravity was high (varying from 1025 to 1030). The relative amount of fixed salts was found to be considerably diminished in the analysis of the urine on the fourth day of the disease; but the decrease had not proceeded to the same extent as in some of 
the other cases, which might have been anticipated, in consequence of the patient progressing so rapidly towards convalescence.

Case $111 .{ }^{1}$ - Timothy Warren, at. 34, married, a strong, healthy-looking, and powerful man, of swarthy complexion and dark hair, was admitted into the hospital on February the 24th, 1851, under Dr. Todd. He was a labourer, somewhat above the middle stature, of temperate habits, and usually in the enjoyment of good health.

On the 19th he was seized with severe headache, loss of appetite, thirst, and shortness of breath, accompanied by cough, and a sharp shooting pain, aggravated by inspiration, and situated immediately beneath the right mamma.

Fifth day of the disease.-On the 24th the following symptoms were noted: face somewhat flushed, and the expression anxious; skin hot and dry. The patient was unable to lie on the right side. He coughed very much, and expectorated rusty mucus. There was severe lancinating pain in the right side. On the lips were the marks of recently healed herpetic eruption. The tongue was dry and brown. On the right side of the chest behind, there was dulness on percussion, over the situation of the lower lobe of the right lung. Bronchial breathing was distinctly heard, and was louder on expiration than during inspiration. Bronchial breathing was also audible over the inner part of the spine of the scapula. Breathing pure in other parts of the chest.

He was ordered milk diet with beef-tea, and to take an ounce of liquor ammonize citratis every four hours. Turpentine stupes were applied to the affected side of the chest. The urine had an acid reaction and a specific gravity of 1017 . One thousand parts contained,-

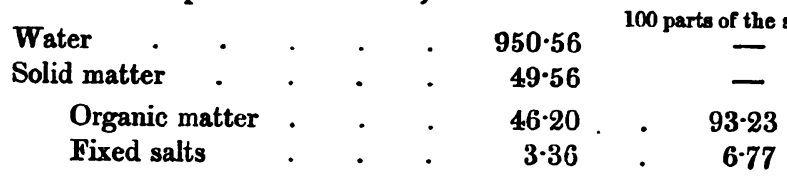


In the fixed salts not a trace of chloride of sodinm conld be detected. The addition of a solution of nitrate of silver to an aqueons solution of the salts acidulated with nitric acid did not even cause the slightest turbidity of the solution. The salts contained much alkaline phosphate.

Sixth day of the disease.-On the 25th the symptoms continued much the same. The expectoration was viscid and rusty. Pulse 110; respiration 44. The patient was ordered to take the saline mixture every two hours, and ten minims of tincture of hyoscyamus were added to each dose.

Seventh day of the disease.-On the 26th bronchial breathing and brochophony were very distinctly heard at the base of the right lung, and were audible over a greater extent of surface than before. The bronchial breathing heard over the spine of the scapula was less distinct, and was accompanied with vesicular breathing. The expectoration was less viscid, and more deeply tinged with blood. Pulse 100; respiration 44.

The urine was of an acid reaction, and its specific gravity was 1015.

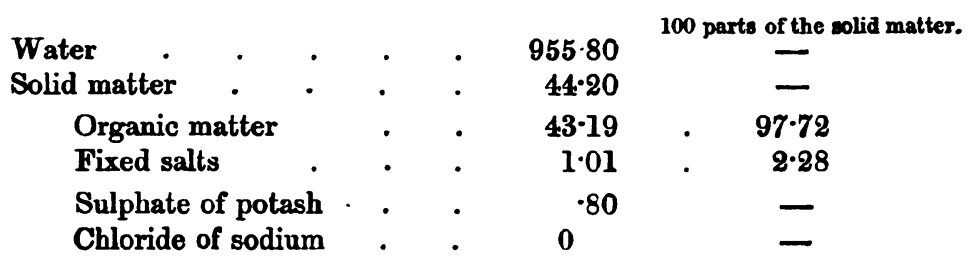

Eighth day of the disease.-On the 27th crepitation was heard in the right mammary region, and was commencing at the base of the lung posteriorly; but in this situation bronchial breathing was still audible, and a dull sound was elicited upon percussion. The pain was quite relieved. Tongue white and coated. Sputa diminished in quantity, but still rusty and viscid. Pulse 96 ; respiration 31.

Urine acid, high-coloured; specific gravity 1020. Contains no albumen. The urine was not farther examined.

He was now ordered to take a pill composed of a grain of calomel and a grain of ipecacuanha every six hours; but one 
pill only was administered. The mixture to be continued as before. A blister was applied to the right side.

Ninth day of the disease. - On the 28th vesicular breathing was heard behind in the lower part of the right side, and was accompanied with very slight crepitation, which, however, became more distinct when the patient took a deep inspiration. Pulse 84; respiration 30.

The sputa were no longer rusty, were less viscid, and were neutral to test paper. 1000 parts were found to contain,-

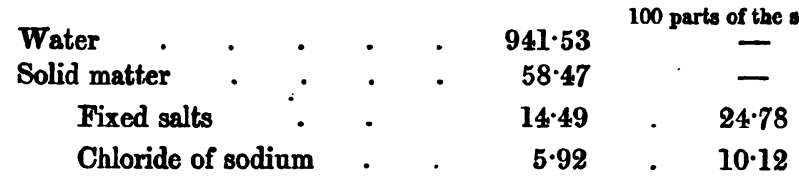

Tenth day of the disease.-On the 1st of March the patient was reported as convalescent. Slight dulness on percussion, however, still remained in the lower part of the right side behind, and the breathing was accompanied with crepitation. Sputa quite clear and much less in quantity. Cough slight. Pulse 80 ; respiration 24.

The urine was again subjected to analysis, and yielded the following results: it was of acid reaction, and its specific gravity was 1020.

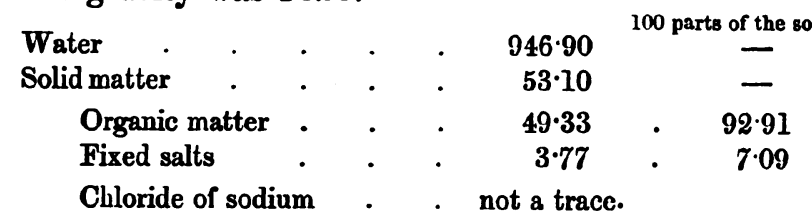

Eleventh day of the disease.-On March 3 the pulse was 64, and the respiration 22. Percussion everywhere resonant. The patient was discharged cured.

In the analyses of the urine of this case the diminution in quantity of the inorganic constituents is well marked, and is very much below the amount found in a state of health. Upon referring to the figures representing the proportion of saline residue contained in 100 parts of solid matter, we find in the first analysis 6.77 , in the second $2 \cdot 28$, and in the third $7 \cdot 09$, while in the healthy urine 25.00 would represent the quantity of fixed salts corresponding to 100 of solid 
matter. It is interesting to observe that on the fifth day of the disease, before the hepatization had developed itself to the full extent, the quantity of fixed salts in the urine was triple that found on the seventh day, about which time the disease was at its height. On the tenth day, after the symptoms of hepatization were no longer present, and the pulse having fallen to 80 and the respiration to 24, and bronchial breathing having been replaced by crepitation, we find a great increase taking place in the quantity of fixed salts, although the chloride of sodium had not yet reappeared in the urine.

The analysis of the sputa on the ninth day of the disease exhibits results of great interest, the saline residue being, in proportion to the organic constituents, unusually abundant.

From an analysis of healthy pulmonary mucus, performed many years ago by Hasse, the quantity of salts corresponding to 100 parts of solid matter amounted to rather more than 18, while in the present instance we find very nearly 25 parts, the exact quantity contained in healthy urine. At the same time it will be observed that the sputa were very rich in the amount of chloride of sodium which they contained, although not a trace of this salt could be detected in the specimens of urine subjected to examination.

In this case of pneumonia the following facts were observed:

1. A diminution of the fixed saline matters, generally, in the urine, and an increase of the organic constituents.

2. A total absence of chloride of sodium in the urine from the fifth day of the disease to the tenth day, when the patient was convalescent, and symptoms of hepatization were no longer to be detected.

3. A remarkable increase, compared with the quantity present in a state of health, in the amount of fixed saline matter in the sputa of the ninth day, (the rusty character having disappeared on the previous day,) and the presence of a considerable proportion of chloride of sodium.

Case Iv.1-James Minns, at. 17; thin and tall, of fair complexion, with light hair and grey eyes. The patient is

1 From the notes of Mr. J. H. Sylvester. 
a waiter in a coffee house, and was admitted into the hospital on February the 11th, 1851, under the care of Dr. Todd. His illness commenced on February the 8th, with loss of appetite, shivering, congh, a sensation of oppression at the chest, accompanied by frequent vomiting, and a sharp cutting pain in the right side. On the 11 th, the usual symptoms of pneumonia had manifested themselves; the patient suffered from troublesome cough, accompanied with viscid, rusty sputa, and in the lower part of the right side of the chest, posteriorly, crepitation and bronchial breathing were audible. Percussion was dull over the situation of the lower lobe of the right lung behind. The respiration was 34, and the pulse 128. It should be mentioned that there was complete absence of vocal vibration in the region, which was found to elicit a dull sound upon percussion. On the 12th, however, vocal vibration returned. The sputa became quite clear on the 14th. The pulse had fallen to 84, and the respiration to 32 . On the 17th, vesicular breathing was re-established, and on the 19th the patient was convalescent. He was discharged on the 2lst. The treatment pursued in this case consisted of the frequent application of turpentine stupes to the affected part of the chest, and an ounce of the liquor ammoniæ citratis was administered every four hours.

On the 11th the urine had a specific gravity of 1020, and upon testing an acidulated solution of the ash with nitrate of silver, a precipitate of chloride was produced.

On the 13th the reaction of the urine was acid, and its specific gravity was 1025. It contained an abundant deposit of lithate of ammonia.

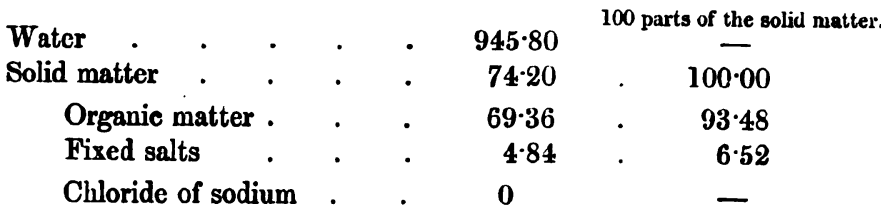

The ash contained alkaline phosphates and sulphates, but not a trace of chloride could be detected upon testing the aqueous solution acidulated with nitric acid, with a solution of nitrate of silver. 
In this case, chloride of sodium was detected in the urine passed on the 11th, at which period the disease may be said to have attained its height, but from this time the quantity, no doubt, rapidly diminished until the 13th, when the presence of chloride was no longer detected. An increase in the amount of the organic constituents of the urine, and a corresponding diminution of the amount of fixed salts, is also observed in the analysis of the urine of the 13th.1

Case v. ${ }^{2}$ - The patient was a young man of the name of Carter, æet. 22, a gentleman's servant, and was admitted into the hospital under the care of Dr. Todd, on March 20, 1851. At the time of his admission he was in a very low and depressed state, and he was occasionally slightly delirious. This condition followed an attack of rheumatic ferer, which had occurred about six weeks previously, and since this attack he had never regained his previous good health. He bad been suffering from want of sleep and loss of appetite, with occasional vomiting. He also complained of seeing spectra about the bed, and his hands trembled very much when he attempted to move them. No evidence whatever could be gained from himself or from his friends of his being of other than temperate habits. His pulse was about 100. He was put upon twenty minims of laudanum every four hours, and in the course of a few days a grain of quinine was ordered to be taken with each dose of the medicine. A few days after his admission other symptoms manifested themselves, among the most important of which, were obstinate constipation, with headache, and dimness of sight. The tongue was moist and coated, and the face flushed. The man was easily startled by the slightest noise, and he was more delirious at night than during the day; and soon the delirium became low and muttering in character.

On March the 26th (six days after admission), symptoms of pneumonia manifested themselves, his pulse had risen

- This, and Case II, were made the subjects of a Clinical Lecture by Dr. Todd, which was delivered in May, 1851, and has since been published in the 'Medical Times' of May the 15th, 1852.

2 From the notes of Mr. E. Siddon. 
from 100 to 186 , and the respiration to 40 . In his other symptoms, no change had taken place. The breathing was laboured and diaphragmatic. Dulness existed over the lower part of the left side, behind, and in this situation bronchial breathing and bronchophony were distinctly audible, but no crepitation whatever could be detected. Over other parts of the chest rhonchus was present. There was no expectoration. It should be observed that on the previous day there was no evidence whatever of the existence of pneumonia.

The urine of March the 26th had an acid reaction, and was of specific gravity 1026.

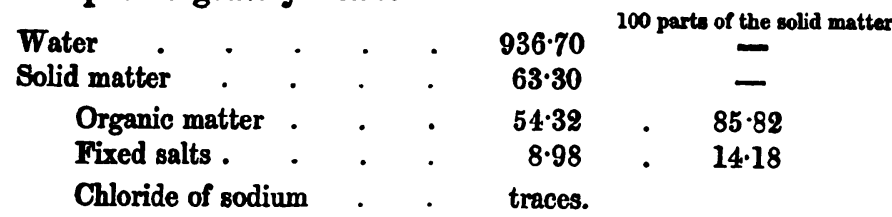

The patient was put upon ounce doses of the liquor ammonix citratis every two hours, and six ounces of brandy were given during the twenty-four hours. A blister was applied to the left side, and turpentine stupes to other parts of the chest. A castor oil enema was also ordered to be administered.

Second day of the Pneumonia.-On March the 27th the patient appeared to be lower. The muttering delirium continued, and the physical signs had undergone no change. The bowels had not been relieved. Pulse 120 ; respiration 40.

The urine was acid, and of specific gravity 1021.

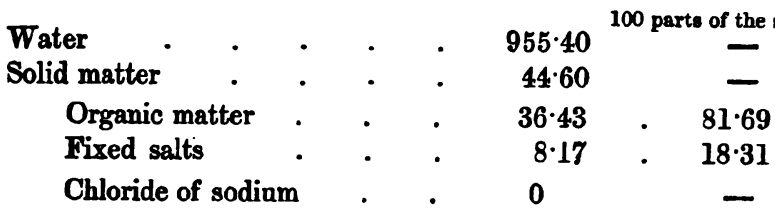

The serum obtained from the blister was also examined: 1000 grs. contained-

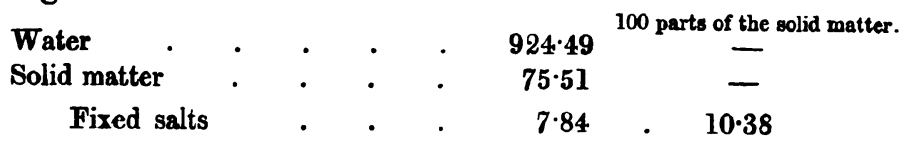


The fixed salts contained much chloride, but the quantity was not estimated.

The brandy was now increased to twelve ounces in the twenty-four hours, and half a drachm of chloric ether was added to each dose of the mixture. The application of turpentine stupes was continued.

Third day of the Pneumonia.-On March the 28th the pulse had risen to 160 , and was very weak and futtering, and the respiration had increased to 44 . The patient was evidently sinking fast. The delirium continued to exhibit the same characters up to the time of his death, which occurred in the evening. His bowels had not been relieved.

The post-mortem examination was performed about thirtysix hours after death. The surface of the brain was much congested, and a considerable quantity of yellowish fluid was found effused in the sub-arachnoid spaces at the base of the brain. In these situations the serous membrane had become quite opaque and very strong, not being easily torn asunder.

The lower lobe of the left lung was found to be much gorged with blood, but it did not sink in water; when a portion was pressed, crepitation occurred, and much dark red blood was squeezed out.

The urine in this case exhibited the chief points which were observed in other instances, although the amount of salts generally was considerably greater than in many of the other cases reported. It is to be regretted that the salts were not further examined, and the amount of the alkaline phosphate ascertained; for, according to the observations of Dr. Bence Jones, a considerable excess of this salt might have been expected in the urine of this case. Notwithstanding the proportion of salts being large, not a trace of fixed chloride could be detected in the urine on the day after the pneumonia had been discovered, although a considerable quantity was found to be present in the serum.

Case vi. ${ }^{1}$-Daniel Henessy, at. 17, was admitted into the hospital, under the care of Dr. Todd, on April the 11th,

1 From the notes of Mr. E. Siddon. 
1851. He said that his mother's family were consumptive, and that he himself had never enjoyed very robust health. For some months previous to his present attack he had suffered from cough, accompanied with profuse expectoration; and about three years previously had been in the hospital, under the care of Dr. Todd, for an attack of pneumonia, from which, however, he perfectly recovered.

On April the 3d he was attacked with rigors and severe pain in the left side, which was much increased upon taking a deep inspiration. At the same time the expectoration, which had been profuse, became scanty, of a rusty colour, and tenacious consistence.

Eighth day of the disease.-The symptoms continued much the same up to the time of his admission, when the pulse was found to be 120 , and the respiration 36 . He complained of feeling very weak, and the pain in the side was severe. Percussion was dull over the situation of the lower lobe of the left lung, and bronchial breathing was audible. Expectoration scanty, and rather rusty in colour. He was put upon ounce doses of the liquor ammoniæ citratis every two hours. Turpentine stupes were applied to the left side of the chest, and afterwards a blister.

Ninth day of the disease.-On April the 12th bronchial breathing was no longer audible, but the dulness still remained. Much crepitation was heard on the left side of the chest. Expectoration fluid and abundant, but not at all rusty. Pulse 108; respiration 32.

The man had passed about two pints of urine in the twenty-four hours, which was high coloured, of acid reaction, and specific gravity 1022.

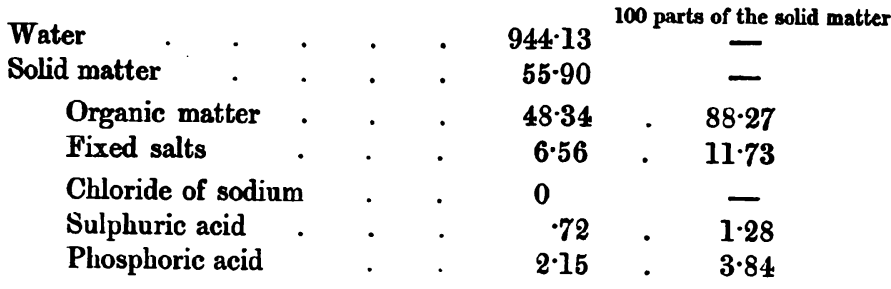

Tenth day of the disease.-On April the 13th the report 
stated that the dulness did not extend over so large a space as before, and that the breathing was still accompanied with a little crepitus.

The urine was acid, of apecific gravity 1022.

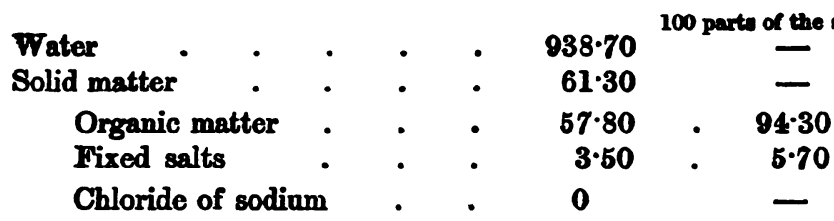

Eleventh day of the disease.-The patient was now convalescent. He was put upon middle diet; and on the 15th he was ordered to omit all other medicine, and to take two grains of quinine three times a day.

His urine was again examined on the 15th. It was of acid reaction, of specific gravity 1026, and contained an abundant deposit of lithate of ammonia.

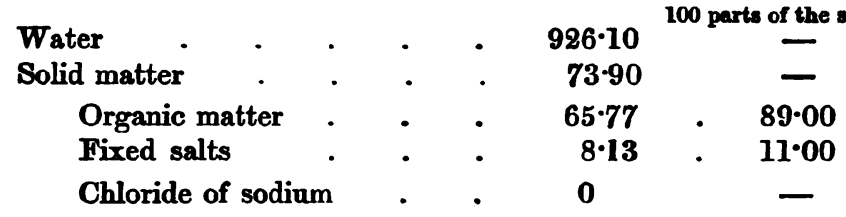

The salts consisted chiefly of alkaline sulphates and phosphates; but not a trace of chloride could be detected in the ash.

In consequence of the patient not recovering his strength so rapidly as could be wished, and also on account of the cough continuing, he was kept in the hospital until May the 14th, when he was discharged well.

In the analyses of the urine of the present case, the diminution of the quantity of salts generally and the increase of organic matter are well marked. The absence of chloride of sodium from the urine, even when convalescence was established, probably depended upon the persistence of the expectoration.

Case vir. - James Regan, at. $\cdot 32$, a compositor, of in- From the notes of Mr. Maurice Davis. 
temperate habits, who nevertheless had enjoyed good health, was admitted into the hospital on May the 12th, 1851, under the care of Dr. Todd.

The patient had been suffering from cough, accompanied with the expectoration of dirty-looking mucus, for some five or six months previous to his present attack. About a reek before his admission he was exposed to cold, by standing for an hour in the street. Eight hours afterwards, pain came on in his left side, and had much increased in severity by the evening. At the same time the cough became more violent, and had gradually increased in frequency up to the time of his admission. The pain in the side had not been relieved.

About the seventh day of the disease.-On May the 12th the following physical signs were noted. Dulness on percussion existed below the left nipple, and in this situation bronchial breathing with some fine crepitation were audible. Posteriorly, below the spine of the scapula, there was also some fine crepitation over the lower part of the left lateral region. On the right side of the chest some rhonchus was heard. The sputa were not rusty, and according to the patient's statement, had not been so; they were, however, very viscid, and firmly adhered to the sides of the vessel that contained them. Pulse 108, respiration 30.

The patient was ordered to take an ounce of the liquor ammoniæ citratis every four hours, turpentine stupes were applied to the chest, and he was put upon milk diet with beef tea.

About the eighth day of the disease.-On the following day, the report was, that the cough was less troublesome, and no bronchial breathing could be detected. Pulse 70, respiration 30.

The urine passed on May the 13th was found to be acid, of specific gravity 1018, and upon analysis, gave the following results:

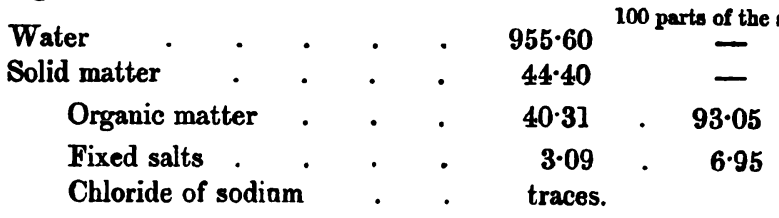


The salts consisted chiefly of sulphates and phosphates. The sputa were now thin and frothy, and did not exhibit the slightest rusty tinge. 395.5 grs. were submitted to analysis, and the results calculated to 1000 parts.

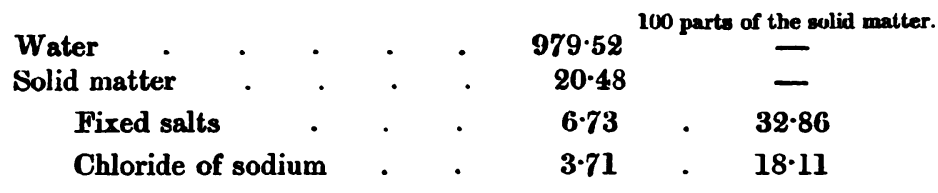

On the 14th diarrhœa came on, for which he was ordered to take chalk mixture with a little laudanum. Fine crepitation was still audible below the spine of the left scapula, and also below the nipple of the same side. Pulse 60 ; respiration 18.

The urine was acid; of specific gravity 1020 ; and contained a deposit of lithates.

On the following day, the crepitation had become, to a certain extent, replaced by rhonchus.

On the 16th, a blister was applied to the back of the left side of the chest, and the serum obtained from it was submitted to analysis :

Water

Solid matte

Fixed salts

Chloride of sodium

$$
927 \cdot 8
$$$$
72 \cdot 20
$$

$8 \cdot 36$

$6 \cdot 45$
100 parts of the silid matter.

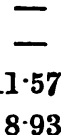

The urine passed on the same day was also analysed, and yielded the following results : it was of acid reaction, and of specific gravity 1020.

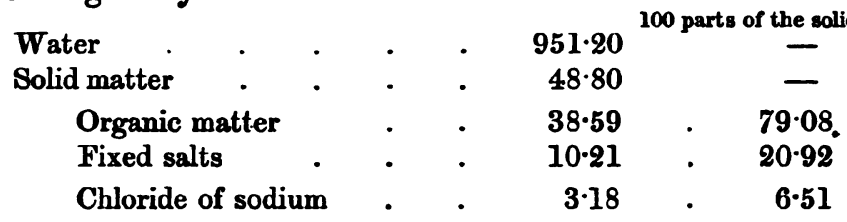

On May the 18th the patient was put upon quinine, and from this time he gained strength daily, and was discharged on the 26th, having bcen fourteen days in the hospital.

A specimen of urine from the present case, was not 
obtained prior to the commencement of resolution of the inflammation. The urine passed on the 13th contained traces of the presence of fixed chloride; but the salts generally scarcely exceeded one fourth of the amount present in healthy urine.

The last analysis of the urine (May the 16th) contained nearly as much saline matter as is found in health, while the chloride of sodium actually exceeded the normal proportion in a slight degree, a fact which receives some explanation from an analysis of the serum obtained from a blister applied on the same day. In that analysis it will be noticed that the chloride of sodium amounts to 6.45 per 1000 , or 8.93 in 100 of solid matter. In health about 4.5 grs. are usually found in 1000 of serum, and about 5.0 grs. in 100 of solid matter.

This great excess of chloride of sodium in the serum of this patient a few days after resolution had commenced, probably depended upon the absorption of a large quantity of the salt which had been previously effused into the air cells at the time when hepatization took place; and this appears still more probable when the fact of the presence of so large a quantity in the urine is considered : for, in the analysis of the urine passed on May the 13th, it was shown that only traces of chloride were present; and in the analysis of the sputa expectorated on the same day, the existence of an abundant amount of chloride was proved. Hence, it would appear that on May the 13th there existed a decided determination of chloride to the lung, and that the force of attraction for this salt was such, as to reduce the quantity of it in the blood so much, that only traces were excreted in the urine. On the other hand, only three days later the attraction of the salt to the inflamed pulmonic tissue had not only ceased, but had given place to a force acting in the contrary direction; and now the chloride of sodium, which in the earlier part of the disease, had been caused to exosmose from the capillary vessels of the lung, by reason of an active cell-forming process proceeding in the inflammatory exudation external to them, becomes reabsorbed by those same vessels, in consequence of the cessation of the cell formation, and the necessary removal of the effused inflammatory products; 
and in this way the excess of chloride present in the serum is to be accounted for.

Case viri. ${ }^{1}$-Samuel Sessions, at. 39, a plasterer; admitted into the hospital under the care of Dr. Todd, on May the 28th, 1851. The patient was a tall, powerful man in an excellent state of nutrition. His general health had always been good; but for many years past he had been troubled with ulcers of both legs, which obliged him to rest for a few days occasionally. On the morning of the 23d he was attacked with a sharp rigor, and a second occurred during the day. Soon afterwards pain came on in the right side, and was accompanied with difficulty of breathing and cough.

Fifth day of the disease. - On May the 28th there was dulness over the central part of the right side of the chest posteriorly, and in this situation bronchial breathing and bronchophony were distinctly audible. Above and below the space over which these signs were heard, slight crepitation was present. The sputa were rust-coloured and viscid. Pulse 96 ; respiration 44.

The patient was put upon an ounce and a half dose of the liquor ammoniæ citratis, every two hours; and turpentine stupes were ordered to be applied to the affected part of the chest, twice in the course of the day.

Sixth day of the disease.-On May the 29th the symptoms were much the same as on the previous day. Crepitation, however, was now audible in front of the right side of the chest, immediately below the mammæ. Bronchial breathing and bronchophony were still heard behind. The sputa were very tenacious and viscid, but only slightly tinged with rust colour. Pulse 104; respiration 38.

The urine was acid; of specific gravity 1015.

\begin{tabular}{|c|c|c|c|c|c|c|c|}
\hline & & & & & & \multicolumn{2}{|c|}{100 parts of the sol } \\
\hline $\begin{array}{l}\text { Water } \\
\text { Solid matter }\end{array}$ & - & & & • & $\begin{array}{r}950 \cdot 90 \\
40.10\end{array}$ & & \\
\hline \multicolumn{2}{|c|}{ Organic matter } & & • & • & $\begin{array}{r}35 \cdot 53 \\
3 \cdot 57\end{array}$ & . & $\begin{array}{r}92 \cdot 73 \\
7 \cdot 27\end{array}$ \\
\hline \multicolumn{6}{|c|}{ Chloride of sodium, not cstimated. } & & 一 \\
\hline
\end{tabular}

' From the notes of Mr. T. Bridgwater. 
The ash of this specimen of urine contained chloride.

The sputa were also subjected to analysis, with the following results :

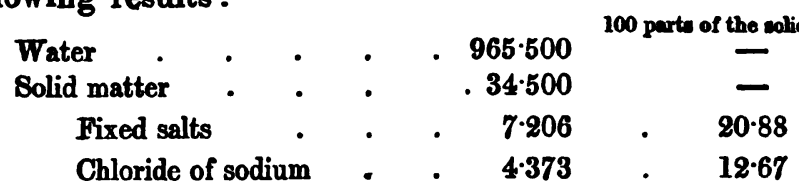

Seventh day of the disease.-On May the 30th bronchial breathing could not be distinguished; but there still remained slight resonance of voice. Pulse 96; respiration 42.

On the following day, the sputa were found to be much less viscid, and the rust colour was now .replaced by an orange-yellow tinge. Crepitation was still audible in the front of the chest, just at the end of a decp inspiration. On the back of the chest, large crepitation was heard. Pulse 72 ; respiration 28.

Tenth day of the disease.-On June the $2 d$ the patient was sitting up. Crepitation was heard behind, at the end of inspiration, and slight resonance of voice still remained.

The urine was again submitted to examination. It was acid, and had a specific gravity of 1022.

\begin{tabular}{|c|c|c|c|}
\hline $\begin{array}{l}\text { Water } \\
\text { Solid matter }\end{array}$ & & $\begin{array}{r}939 \cdot 80 \\
60 \cdot 20\end{array}$ & - \\
\hline $\begin{array}{l}\text { Organic matter } \\
\text { Fixed salts }\end{array}$ & & $\begin{array}{r}50 \cdot 83 \\
9 \cdot 37\end{array}$ & . \\
\hline
\end{tabular}

The salts contained distinct traces of chloride of sodium.

The patient gradually improved, and was discharged quite well on June the 11th, nineteen days from the commencement of his illness, and fourteen days after his admission.

Case 1x. 1 - James Flynn, at. 44, an Irish labourer of very intemperate habits. He was a strong, healthy looking, working man, somewhat above the middle stature, with black curly hair and dark eyes. He stated that he had

- From the notes of Mr. J. Cheath. 
never suffered from any form of illness previous to the present attack. This man was admitted into the hospital, under the care of Dr. Budd, on December the 16th, 1851.

The first symptoms appeared during the night of December the 13th, when he awoke from sleep with a sharp pain in the lower part of the right side. The pain was increased by coughing, or by taking a deep inspiration. Soon afterwards he felt hot and thirsty, and then, he said, he began to sweat a good deal. He also suffered from loss of appetite, but had not been seized with rigors. The patient said, that on the 13th, he worked very hard all day, and got wet footed, but, nevertheless, felt perfectly well when he went to bed.

Second day of the disease.-On December the 14th slight cough came on, and was accompanied with expectoration, which at first was colourless, but soon became of a brownish hue.

Fourth day of the disease.-On December the 16th he complained of much pain in the lower part of the right side, the pain being increased by cough, and also by locomotion. The cough was frequent, but not violent, and was accompanied by the expectoration of much rusty-coloured mucus, which rather inclined to a greenish hue, and was not very tenacious. The tongue was white and furred. The lower half of the right side of the chest behind, was found to be dull on percussion; in this situation, vocal vibration was increased, and the breathing was tubular in character. In other parts of the chest the respiration was vesicular, but loud, and the resonance was unimpaired, except in that portion of the chest which corresponds to the lower lobe of the right lung. Pulse 96 ; respiration 36.

He was ordered to take an ounce and a half of liquor ammoniz citratis, with half a drachm of antimonial wine every three hours. A purge of sulphate and carbonate of magnesia was given, and turpentine stupes were applied to the affected part of the chest every two hours. He was put upon low diet and beef tea.

The urine passed in the evening of December the 16th was high coloured, of acid reaction, and of specific gravity 1022. 


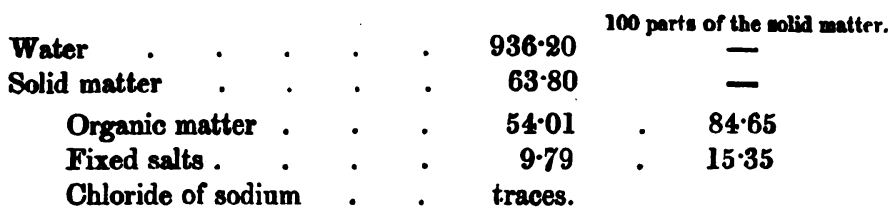

The aqueous solution of the saline matter became only slightly milky upon the addition of a solution of nitrate of silver, and a few drops of nitric acid.

The salts consisted chiefly of sulphates.

Fifth day of the disease:-On December the 17th bronchial breathing was heard distinctly over the lower part of the chest behind, and it extended rather higher up the chest than the point at which tubular breathing had been audible the day before. Small crepitation was heard during inspiration. The patient said that the pain in the side had been somewhat relieved. The skin was moist. Pulse 96 ; respiration 28.

The sputa were slightly frothy, of a brown colour, and in consistence and general appearance, much resembled very thick mucilage. The reaction was neutral, and the specific gravity 1014.

Upon the application of heat a bulky precipitate of albumen was thrown down.

491.5 grains of the sputa were submitted to analysis, and the results calculated to 1000 parts.

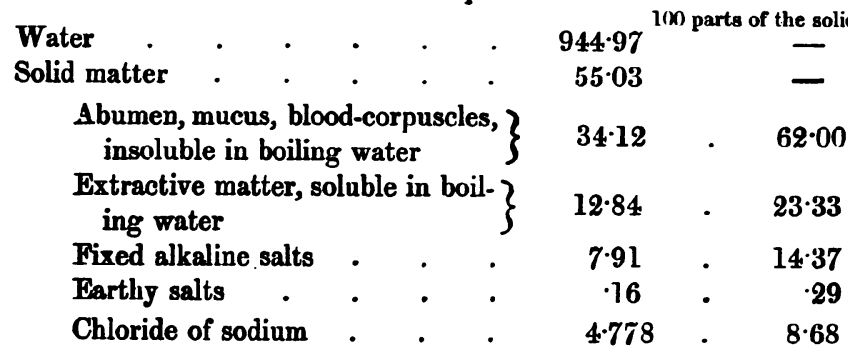

Sixth day of the disease.-On the 18th, the same physical signs that were detected on the previous day were present over a much greater extent of surface, and the report says, that " nearly the whole of the right lung appeared to be involved in the inflammation." Pulse 102 ; respiration 42. 
In the evening, the pulse was 96, and the respiration 36 . He was now ordered to take two grains of calomel, and a quarter of a grain of opium, every three hours, and a quarter of a grain of tartarised antimony with an ounce and a half of liquor ammoniæ citratis, as before.

Seventh day of the disease. - On December the 19th he was free from pain, but his cough was more frequent, and his sleep had been disturbed. Dulness was present over the lower two thirds of the right side of the chest, both before and behind. No breathing whatever was audible over the greater part of this portion of the chest, but quite at the lowest part, tubular breathing was present, with a little fine crepitation, and loud vesicular breathing was heard in the upper part of the right side, corresponding to the situation of the upper lobe of the right lung.

The patient had not been nauseated by the antimony, but he complained of drowsiness. The calomel and opium were ordered to be discontinued. Pulse 108 ; respiration 36.

The urine was of acid reaction, and its specific gravity was 1023.

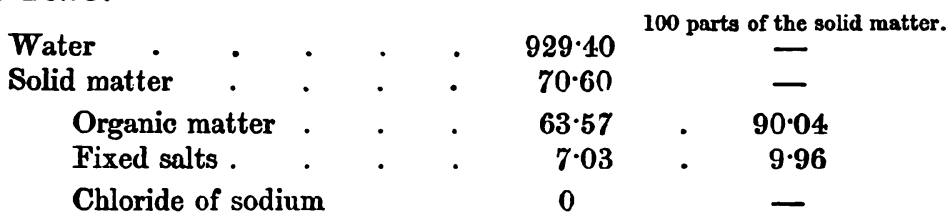

The sputa exhibited a slightly acid reaction, and the specific gravity was 1028. The secretion was not so viscid as the specimen examined on the 17th. Upon the application of heat, or upon the addition of nitric acid, the mass became almost solid from the coagulation of albumen.

The sputa wcre tested for sugar by Trommer's test; when the solution was boiled, it became dark blue, and subsequently brown, but no suboxide was precipitated. The same phenomena were observed when the solution of double tartrate of copper (as employed by $M$. Bernard in his well known experiments) was substituted for the former test. ${ }^{1}$

- To Dr. Todd I am indebted for the suggestion of testing pncumonic sputa 
196.2 grains of sputa were submitted to analysis, and the result calculated to 1000 parts.

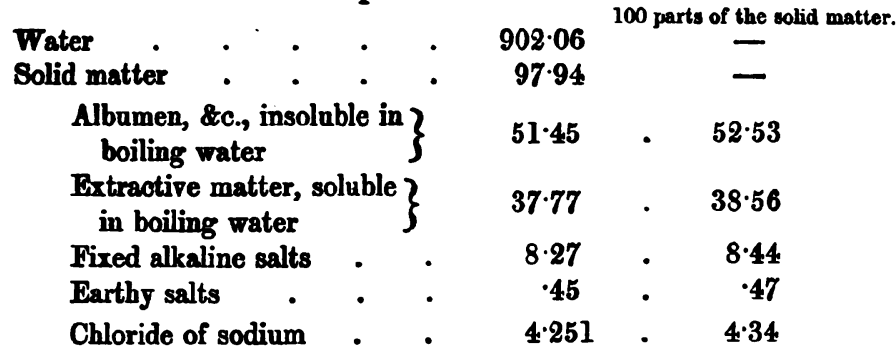

Eighth day of the disease.-On the 20th the patient appeared to be in much the same state as on the previous day. The cough was somewhat looser, and the expectoration was abundant. Bronchial breathing was audible over the lower two thirds of the chest behind, and over the upper lobe, the respiratory sound was very loud, and mixed with crepitation. The breathing over the left side of the chest, was vesicular and puerile. Skin cool and perspiring. Pulse 132; respiration 42.

About 8, P.M., his breathing became much quicker and more feeble, and from this time he sank very rapidly, and died about an hour afterwards.

The sputa expectorated on the 20th were less viscid than on the day previously, and exhibited more of the prunejuice character. The reaction was very acid, and the specific gravity was 1032-8.

Upon boiling a portion with a solution of sulphate of copper and potash, much suboxide of copper was thrown down, and fell to the bottom of the test-tube, in the form of a pale brown precipitate, showing the presence of a considerable quantity of sugar in the sputa of this patient, the portion examined being the last that he expectorated. The presence of sugar was confirmed by the tartrate of copper

for sugar; he considered that if the views of Bernard, regarding the changes taking place during respiration, were correct, sugar ought to be present in the sputa of pneumonia in sufficient quantity to be recognised by the ordinary tests. 
test. A portion of the sputa was examined by the microscope, and the following appearances were observed :Numerous blood corpuscles were present, and much brokendown epithelium and granular matter, with cells of various forms having granular contents, were observed. There were also some granular cells which, in their general appearance, much resembled pus globules; but, upon the addition of acetic acid, no central nuclei-like bodies, so characteristic of the pus corpuscle, were developed. A few large and fine oil globules, with many small oil globules and much granular matter, were also present.

393.6 grs. were submitted to analysis, and the results calculated, as before, to 1000 parts :

Water . . . . . . . . $\quad$. $865 \cdot 86$

Solid matter $. \quad . \quad+\quad . \quad+\quad . \quad 134 \cdot 14$

Albumen, \&c., insoluble in boiling water $\quad 56.325 \quad$. $\quad 41.99$

Extractive matter, soluble in boiling water $67 \cdot 150$. 50.07

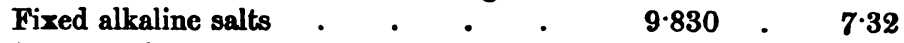

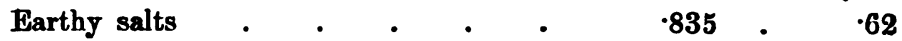

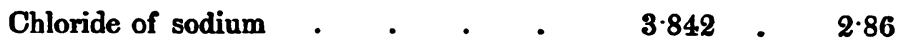

A portion of the urine found in the bladder at the postmortem examination (forty-two hours after death) was submitted to analysis. This specimen had a very offensive odour, was of acid reaction, and of specific gravity 1018. Separate portions were tested for sugar, with the two tests before mentioned, but not the slightest change, indicative of the presence of sugar, occurred.

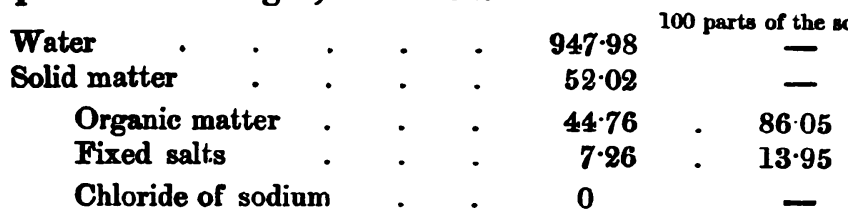

The fixed salts consisted chiefly of sulphates.

Post-mortem (forty-two hours after death). - Slight pleuritic adhesions, which were readily broken down, were found on the left side of the chest.

The right lung was completely hepatized, with the excep- 
tions of a strip, about half an inch in depth, on the anterior aspect of the upper lobe, and also a superficial strip on the posterior surface of the lower lobe. In these situations, the tissue appeared healthy, and crepitation occurred upon slight pressure. In all other parts, the right lung was quite solid, and small pieces cut off in different parts of the organ, sank in water, and not even the slightest crepitation could be produced by firm pressure. The smaller bronchial tubes were completely choked up, some with corgulated blood, others with plugs of pure fibrin. Upon making sections of the lung, a few patches of grey hepatization were observed, and everywhere, the lung was easily broken down between the finger and thumb, into a dark red pulpy mass. From the freshly-cut surfaces, a prune-juice-like fluid was poured out, which in its appearance much resembled the sputa expectorated by the patient during the last two days of his life. The left lung was somewhat congested, but otherwise appeared healthy. In some places, however, patches of highly congested tissue were observed.

The heart was healthy; and nothing abnormal was observed in the condition of the liver or kidneys. No other organs were examined.

Being anxious to ascertain the changes which had taken place in the composition of the blood, more particularly with reference to the amount of chloride it contained, a portion, consisting of clot, colourless fibrin, and serum, was taken from the right side of the heart and was submitted to analysis. The amount operated on weighed 775.7 grs. The results obtained, being calculated to 1000 parts, gave the following as the composition of the blood:

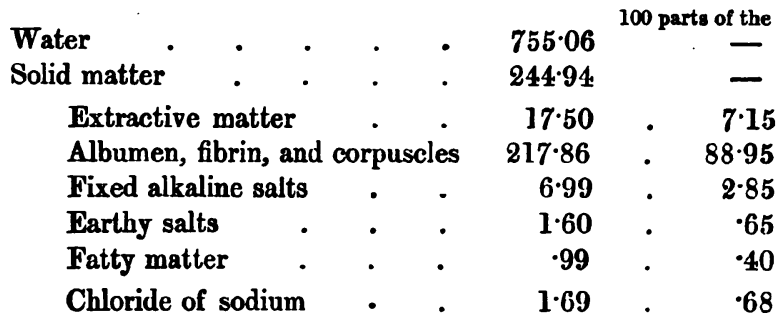

The fatty matter consisted almost entirely of cholesterin. 
A portion of each lung was submitted to analysie, with the following results :

Analysis A represents the composition of that part of the right lung which was found in a state of red hepatization, the patches of grey hepatization being carefully excluded. The specific gravity of the portion selected, was 1051.6. 898.18 grs. were evaporated to dryness.

Analysis B represents the composition of the left lung, the portion selected for examination being that which appeared most healthy and free from congestion. 328.47 gre. were evaporated to dryness, and the result obtained calculated to 1000 parts, as in the previous analyses.

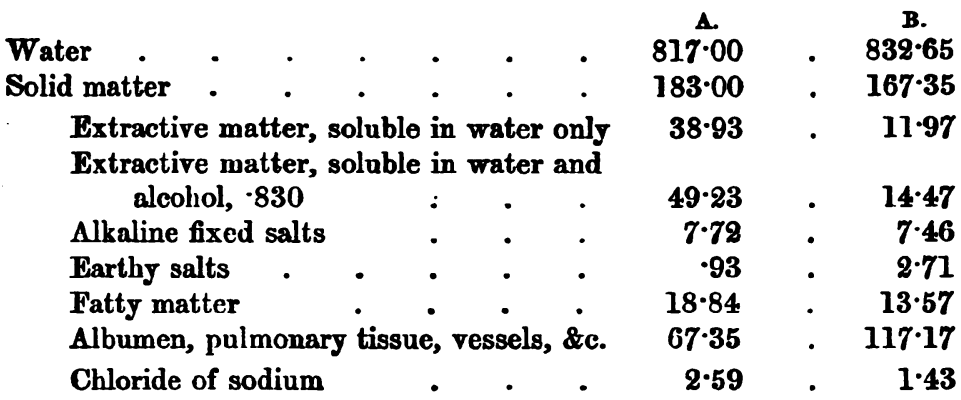

From the data obtained in these analyses, the composition of 100 grs. of solid matter of the lungs was calculated :

Solid matter

A.

B.

Extractive matter, soluble in water only

Extractive matter, soluble in water and alcohol, $\cdot 830$

$\begin{array}{rrr}100 \cdot 00 & . & 100.00 \\ 81.27 & . & 7 \cdot 15 \\ 26.90 & . & 8 \cdot 65 \\ 4.22 & . & 4.46 \\ .51 & . & 1 \cdot 61 \\ 10.29 & . & 8 \cdot 11 \\ 36 \cdot 80 & . & 70.01 \\ 1.41 & . & .85\end{array}$

The fatty matter obtained from the pneumonic lung consisted chiefly of dark brown oily fat, and only a few plates of cholesterin crystallised out upon slowly evaporating an 
alcoholic solution, while from the alcoholic solution of the fat obtained from the healthy lung much cholesterin separated, in the form of beautiful and well-defined crystals.

A portion of an aqueous solution of the extractive matters soluble in boiling water, which was obtained from the hepatized lung, was tested with Trommer's test for sugar. Upon boiling, the mixture became of a beautiful dark purple colour, but no suboxide of copper was precipitated. The absence of any indications of the existence of sugar in the solution, when tested by Trommer's test, may be accounted for by the long interval of time which had elapsed since the man's death, before the application of the tests ; for it has been shown that all traces of the presence of sugar in the liver, vanish a few hours after death. If, however, the liver of a person recently dead be tested for this substance, its existence may always be proved, according to the experiments of Bernard. Moreover, the indications of the presence of small quantities of sugar, might be entirely masked by the very deep colour which the solution assumed upon boiling; and it was therefore considered better to apply the yeast test, before any positive conclusion was adopted.

Twenty grains of the aqueous extract of each lung (obtained by treating the desiccated lung with boiling water, and subsequent evaporation of this solution to dryness,) were dissolved in two equal quantities of distilled water; and to each solution a similar amount of yeast was added, the mixture being placed in test-tubes inverted over mercury. A third test-tube of equal size to the former, was filled with distilled water mixed with the same quantity of yeast, as placed in the other tubes. The whole was kept in a warm place for two days, at the end of which period, the tubes were removed, and the bubble of gas which had formed was measured.

The tube containing yeast and water contained 04 of a cubic inch of gas.

The tube containing the solution of the extract of the healthy lung was found to contain $\cdot 06$ of a cubic inch of gas. 
The third tube, in which the solution, of the extract obtained from the hepatised lung was placed, contained .09 of a cubic inch of gas.

Although the amount of gas obtained in each case was so small absolutely, the difference in quantity is 80 striking in the three cases, that it appears to justify the inference of the presence of sugar, at least in the hepatised lung, if not also in the sound lung to a less degree. The blood was not tested for sugar.

The phenomena observed in the urine of the present case were very similar to those met with in the urine of other cases of pneumonia. A considerable increase in the quantity of the organic constituents, and great diminution in the relative amount of salts, with a total absence of chloride of sodium after the fourth day of the disease, will be noticed. It will be observed that the diminution of the salts did not pruceed to so marked a degree as in several of the other cases, which fact is to be accounted for by the patient having taken a considerable quantity of sulphate of magnesia as a purgative, much of which salt escaped by the urine, and thus increased the amount of salts taken collectively.

An analysis of the sputa was made three times in the course of the disease, namely, on the fifth, seventh, and eighth days; and the chief changes which took place in its composition may be observed by reference to the following Table, in which the composition of $100 \mathrm{grs}$. of the solid residue of each specimen examined, with the reaction and specific gravity, are set down :

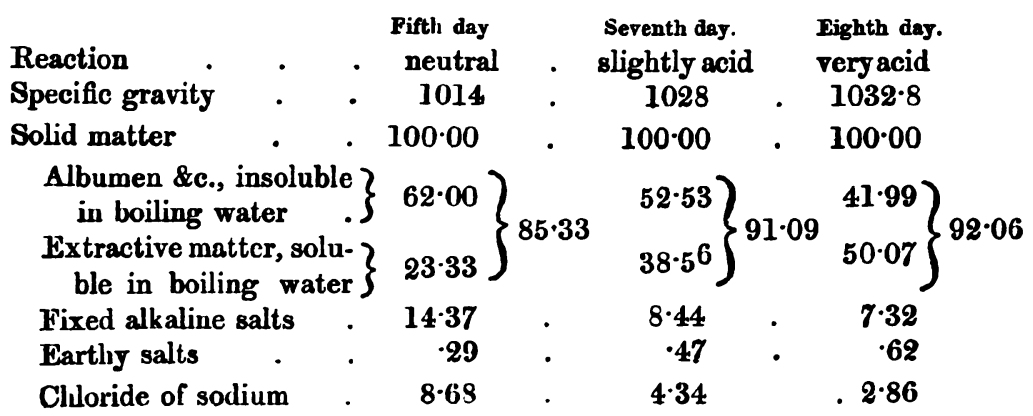


The changes which occurred in the reaction of the sputa from day to day, terminating in the production of very acid expectoration, may perhaps be referred to the development of an increased quantity of the peculiar acid which is formed in the lungs, and which, according to Verdeil, in healthy respiration is neutralised by the decomposition of the car. bonate of soda of the blood, the soda uniting with the acid of the pulmonary tissue, and the carbonic acid being expelled in the process of respiration. In the latter stage of pneumonia, the circulation through the lung being retarded or completely obstructed, it seems not unreasonable to suppose that the necessarily diminished quantity of alkali brought to the lungs, in consequence of the impediment to the circulation, is insufficient to neutralise the free acid secreted by the pulmonary parenchyma, which, therefore, accumulates, and causes the sputa to exhibit a highly acid reaction.

The increasing specific gravity of the sputa depended chiefly on the increasing amount of solid constituents which these specimens were found to contain. The first specimen of expectoration contained 55.03 grs. of solid matter in 1000 grs., the second $97 \cdot 94$ grs., and the third 134.12, in the same quantity. This increase of the solid matter in the sputa as the disease progressed towards a fatal termination, is perhaps no more than would have been anticipated, and may doubtless be referred to the gradual softening and breaking down of the inflammatory products effused into the air-cells of the lung, and is also, perhaps, in part dependant upon the destruction of the pulmonary tissue itself. The vessels distributed on the air-cells being either entirely destroyed or rendered quite impervious, it becomes altogether impossible that any of the disintegrating mass can be absorbed; and hence it continues to be expectorated, until this last effort of nature for its removal becomes thwarted by the complete failure of the patient's strength, which terminates in his death.

The next point worthy of notice in the above analyses is 
the gradual increase, from day to day, of the extractive matter soluble in boiling water, at the expense of the albumen, fibrine, and blood-corpuscles contained in the sputa. In the second and third analyses this is well shown; for while the united quantities remain very nearly the same in each case, it is to be noticed that on the seventh day of the disease the inooluble matter amounted to 52.53 and the soluble to 38.56; but in the analysis of the sputa on the following day these figures were nearly transposed, the insoluble matter being then diminished to 41.99 , while the soluble portion was increased to 50.07; or, taking the three analyses together, we find the insoluble portion on the three days represented, in round numbers, as follows : 62, 52, 42, and the soluble matter by the numbers 23, 38, 50. Hence it appears that the albumen and fibrin, which are probably the chief substances concerned in the changes which take place in the production of hepatization of the lung, and which, especially the latter, enter largely into the composition of the sputa, become, at a certain period of the disease, so altered in their chemical characters, as to partake more of the nature of extractive matters, which are soluble in boiling water, and in their general appearance and taste agree with the extractive matter of the blood. This tends to show that the extractives may, under some circumstances, be produced by the immediate metamorphosis of albuminous matter.

The diminution from day to day in the quantity of fixed salts in the sputa, depends doubtless upon the gradual elimination of the saline matter from the blood, without a compensating amount being taken among the ingesta; and the gradually decreasing quantity of the fixed salts in the urine, so well marked in some of the cases reported, depends partly on the same cause; but I believe that the diminution is also, in great measure, due to the determination of the saline matter to the inflamed pulmonary tissue; for it may be remarked in Cases I, III, vi, and vir, that as soon as resolution was fully set up, and the patient was decidedly progressing 
towands recovery, a great increase in the relative amount of calts excreted by the urine occurred, while no change which would account for such an alteration had been made in the patient's diet, or in the treatment to which he was subjected.

That in such a morbid condition of lung a certain amount of attraction for the saline constituents of the blood really exists, is borne out by the fact, that while 1000 grs. of sputa expectorated just before death contained 9.83 grs. of fixed salts, the same quantity of blood taken from the heart after death was found to contain only 6.99 grs.; or in 100 grs. of the solid matter of the sputa $7 \cdot 32$, while in 100 grs. of the solid matter of the blood only 2.85 grs. of fixed salts were present.

The amount of fixed chloride present in the sputa was estimated in Cases III, vir, and virI; and in each instance a considerable proportion was found to be present. At the same time it was shown that mere traces of this salt existed in the urine, or it was entirely absent from this fluid; from which it was inferred that the amount of chloride of sodium present in the blood was considerably less than would be found in a state of health. The solid matter of healthy urine usually contains about five per cent. of fixed chloride. In Case vil it was proved experimentally that the amount of fixed chloride in the urine might be taken as a rough index of the quantity existing in the serum at the same period; for the solid matter of the urine was found to contain rather more than the healthy proportion of this salt, and an excess was also present in the serum obtained from a blister. In the last case reported a deficiency of salt was found in the blood, while the urine did not contain a trace.

In the following Table I have introduced, for the sake of comparison with the composition of the sputa in the three cases of pneumonia just referred to, an analysis of the mucus of the nostrils and trachea by Berzelius, and an analysis of a tracheal and bronchial mucus, obtained from a patient who died during the existence of active symptoms of influenza, 
by Dr. Wright. In order that the results obtained by myself, with reference to the peculiar character of the pneumonic sputum, may be the more readily compared with those obtained by Berzelius in healthy sputum, and by Dr. Wright in the sputum of influenza, $I$ have reduced the two latter analyses to the per-centage composition of the solid matter, and have altered their form of expression for the convenience of tabulation :

\begin{tabular}{|c|c|c|c|c|c|}
\hline & $\begin{array}{r}\text { Berzelius. } \\
100 \cdot 0\end{array}$ & $\begin{array}{l}\text { Infuenza } \\
\text { Dr. Wright } \\
100 \cdot 0\end{array}$ & $\begin{array}{c}\text { Pneumonia } \\
\text { Case S. }\end{array}$ & $\begin{array}{l}\text { Pueumonia } \\
\text { Case } 7 .\end{array}$ & $\begin{array}{l}\text { Preamonis } \\
\text { Case } 8 .\end{array}$ \\
\hline & - & 11.9 & 94.78 & 39.86 & 90.67 \\
\hline diun & $8 \cdot 4$ & - & $10 \cdot 12$ & $18 \cdot 11$ & $12 \cdot 67$ \\
\hline
\end{tabular}

In Berzelius' analysis, the total quantity of fixed salts did not probably exceed 12 or 14 grs. in 100 of solid matter; and it is obvious that in Dr. Wright's analysis the chloride did not nearly amount to the quantity present in the three other cases, since the total quantity of salts was only 11.9 grs.

The expectoration in the case of Flynn (Case Ix) formed

1 Dr. Wright's Papers on the Pathology of Expectoration.- 'Medical Times,' vol. xi, p. $200 ; 1845$.

\section{Berzelius' Analysis.}

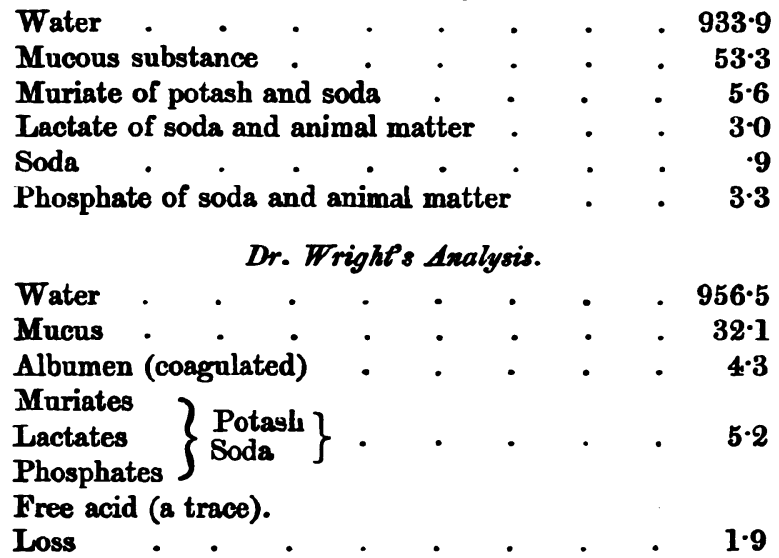


an apparent exception to that of the cases above referred to; for an unusually amall quantity of chloride was present, and by reference to the analysis of the sputa on the fifth, seventh, and eighth days of the disease, a gradual decrease in the amount of fixed chloride will be observed, which cannot but be regarded as an interesting point in the pathological changes which accompany pneumonia, when considered in connection with those which were taking place in the chemical composition and microscopical characters of the matter poured out into the air-cells of the lung. This decrease in quantity of the alkaline salts generally, and more especially of the chloride of sodium, is probably intimately connected with the softening and breaking down of the solidified lung into a soft and pulpy mass. It has been long known that chloride of sodium acts as a powerful preventive of the decomposition and destructive disintegration of animal substances, and its great importance to the process of cell development and growth will be presently considered.

Although the amount of chloride present in a certain quantity of sputa in Case $1 x$ was unusually small, it nevertheless considerably exceeded the proportion in the blood at the same period of the disease, (in the last analysis 1000 grains of sputa contained $3 \cdot 842$ grains of chloride of sodium, while only 1.69 were present in a similar quantity of blood, or in 1000 grains of solid matter 2.86 in the former and -68 in the latter.) In all the other specimens of sputa subjected to examination a considerable proportion of this salt was found to exist, although it was entirely absent in the urine, or traces only were detected. In the case of Regan, the solid matter of the sputa contained a very large proportion of salt, which, in conjunction with other facts, I considered as tending to show that in pneumonia there existed a determination of chloride of sodium to the inflamed lung. It appears difficult to account for the presence of so great an excess in the sputa unless the existence of some attractive force be admitted, particularly as it has been 
shown that if an excess of ehloride exist in the blood, a considerable quantity is excreted by the kidneys. Hence, if a large proportion of chloride be found to be present in the sputa, as in the cases above mentioned, and there exist in the blood, at the time of the secretion of the sputa, a proportion less than that found in health, as was shown by the existence of mere traces in the urine, it follows, I think, that the excess of chloride in the sputa depends upon an exalted attraction for chloride on the part of those textures concerned in the formation of the characteristic expectoration of pneumonia. The precise tissue concerned in the secretion of the viscid sputa which contains so much chloride is probably the mucous membrane of the smaller bronchial tubes, for it has doubtless the office of separating a certain quantity of saline matter from the blood in a state of health, and therefore when the mucous membrane is inflamed, and cell formation is more actively taking place in the finer ramifications of the bronchial tubes, a more abundant secretion of the substances concerned in the building up of these cells must take place. The development of mucous corpuscles, and those peculiar cells containing minate oil globules, which are usually found in the ordinary pulmonary mucus, and which are so abundant in the sputa of pnenmonia, is probably intimately connected with this separation of saline matter from the blood.

Whether chloride of sodium be essentially necessary to the growth and development of the peculiar non-nucleated cells, to which reference has just been made, I have not yet been able to determine by my own observations; but in many instances in which these bodies were abundant, the presence of much saline matter which contained a considerable proportion of chloride of sodium was proved.

In the mucus expectorated in pneumonia, provided there exists in the system a sufficient quantity of chloride of sodium (although this may be much less than is present in health) there appears to be present a greater proportion of this salt relatively to the amount of the other constituents 
of the sputa than in healthy pulmonary mucus, but in cases in which the disease had continued for some days, so that time had been allowed for the elimination of much chloride from the system in the expectoration, while little or none had been taken in the food, an excess in the per-centage of chloride in the sputa can scarcely be expected.

Although only a small proportion of the chloride may be found in a given quantity of the sputa submitted to analysis, yet when this was calculated in the total quantity of sputa expectorated, and added to the amount present in the inflammatory exudation still remaining in the lung, the whole quantity would be something considerable, particularly in a case like that of Flynn (Case Ix) where one lung was completely hepatized. It cannot be urged as an argument against this supposed exalted attraction of the inflamed lung for fixed chloride, that the relative proportion in a certain quantity of sputa more nearly approximates to the amount present in a similar quantity of blood than in health, for, in consequence of the affinity of albumen for a certain quantity of chloride of sodium, (it being quite impossible to separate all traces of this salt from albumen by washing,) it follows that the excretion of the salt from the blood cannot continue until this fluid is completely deprived of it. If, however, the ordinary amount of chloride were present in the system generally, which may be inferred if the urine is found to contain its normal proportion, the relation existing between the amount present in given quantities of blood and sputa, or in a certain quantity of the solid matter of these two fluids, would be found to exhibit a more striking difference, than when the chloride of sodium existing in the system is reduced to a standard much below that of health. An example may perhaps render my meaning more intelligible.

In Flynn's sputa (Case Ix), just previous to his death, after much chloride had been removed from the system, while a considerable quantity still remained in the lung, and when the urine for several days had ceased to afford 
the slightest indication of the presence of this salt, $100 \mathrm{grs}$. of the solid matter were found to contain only 2.86 of chloride, while the solid matter of the blood contained $\cdot 68$ per cent., which is in the proportion of about four to one. In Hasse's analysis the difference in quantity would be considerably greater, and would be somewhat less than eight to one, or nearly double. However, upon reference to the analysis in Regan's case (Case vir), where the chloride in the system did not exceed the healthy standard, for the urine only exhibited traces of the salt, the sputa expectorated upon the same day as that on which the urine was examined contained in 100 grs. of solid matter as much as 18.11 grs. of fixed chloride, which would be in the proportion of nearly ten to one, (that is, supposing his blood at the time to contain as much chloride as is present in a state of health, which there is reason to believe was not the case at this period.) Two days later, when resolution of the inflammation was clearly taking place, the urine was found to contain 6.51 in 100 grs. of the solid matter, and the serum $8.93 \mathrm{grs}$. in the same quantity, which unquestionably showed that the chloride originally effused into the inflamed lung had been reabsorbed by the blood, and was now passing off in the urine.

The determination of chloride of sodium to the inflamed lung in cases of pneumonia, is perhaps a fact, which, from analogy we should expect to find; for, from the analyses of various observers, it appears that a large quantity of chloride of sodium is present whenever the metamorphoses of tissues depending upon cell development is going on ; and that such an increase of the chloride should be observed to take place in those pathological conditions in which cell formation takes so active a part, is exactly what one would expect, seeing that the farther investigation is carried, the greater reason do we find for believing that the pathological changes which are observed in various tissues are governed by, and take place in obedience to the same fixed laws which regulate certain physiological changes, but acting under different relations. 
In reference to this interesting point it may be remarked generally, that in a state of health those secretions which are elaborated by an abundant formation of epithelium contain a greater proportion of chloride of sodium than is present in those fluids which are poured forth from surfaces covered sparingly with epithelium, which, perhaps, takes but a small part in the secreting process. Of instances of the former class of secretions, may be mentioned the saliva, the gastric juice, the sweat, the tears, and mucous secretions generally, - among the latter class, the milk, and the secretions of serous and synovial membranes in health, may be referred to as examples. Urine may be placed intermediately between these two classes, and biliary secretion is found to contain less chloride than urine; but much more than is found in milk.

In the development of tissues in the embryo, a large proportion of fixed chloride is present. In the growing femur of a six months' fœtus, Lehmann found 10.138 per cent. of chloride in the ash, while from the ash of adult bones he could only extract from 0.7 to 1.5 per cent.; and Voigt found in the liquor amnii of a fœtus, about the fourth month, 5.95 per 1000 parts, while in the sixth month he only obtained $2 \cdot 4$ in the same quantity.

The peculiar sallowness of the complexion which has often been observed to ensue after the occurrence of hepatization of the lung, in cases of pneumonia, may be due, in part at least, to the altered colour which the blood assumes in consequence of a deficient quantity of chloride of sodium, for the mere circulation of blood which had been but imperfectly aerated, would not account for the chlorotic appearance which is often present. A deficiency of chloride of sodium in the blood has been observed by Mulder, and others, in cases of cholera; and a marked diminution has been met with in chlorosis, by Becquerel and Rodier, who found only $2 \cdot 6$ grs. per 1000 in one instance of this disease, in which, however, the corpuscles amounted to 123.8, and the solid matter to $201 \cdot 4$ per 1000.

XXXV. 
In the case of Flynn, where the sallowness of the complexion was well-marked, and came on soon after the occurrence of hepatization, I found that the blood contained only 1.69 per 1000 , although the solid constituents amounted to 244.94. This man upon his admission had a very florid complexion. It is not improbable, that the excess of chloride of sodium in the sputa of pneumonia produces that modification in the colouring matter of the blood that is effused, which distinguishes pneumonic expectoration from every other form.

Chloride of sodium forms one of the most important saline constituents of the animal body, and in many of the secretions the quantity of this salt equals, or even exceeds that of all the other inorganic ingredients put together; notwithstanding its great abundance in many of the animal juices, the variation in quantity of the salt in different secretions, or in the same secretion under certain altered conditions has as yet scarcely received that attention from pathologists which the subject appears to deserve.

The high diffusive power of common salt, as has been shown by Professor Graham,-the readiness with which it permeates, animal tissues,_-its great solubility in water,-its preservative powers-its wide distribution over the surface of the earth, and throughout the whole organic kingdomthe avidity with which it is sought after by man and animals, which for a time have been deprived of its use,and its abundance in growing embryonic tissues, which in their mature state contain only traces of it, all point to its importance as a constituent of the living organism; and the study of the different quantities of salt existing in various tissues in a state of health, and also under certain morbid conditions, appears to me likely to elicit some interesting points in reference to the especial part performed by the salt in cases of cell growth and multiplication, and the importance of the salt to reparative action suggests the propriety of supplying our patients with a sufficient quantity in certain cases of disease. 
The most important changes which take place in the chemical composition of the lung when it becomes hepatised, are represented in the following analysis :

In comparing an analysis of hepatised lung with one of sound lung, it may be observed that the comparison is not made between equal bulks of pulmonary tissue, but between equal weights of lung, in two very different states, and hence the difference in composition is perhaps not quite so great as might at first be expected. In an analysis of a certain weight of sound lung, the composition of the lung tissues with a certain proportion of blood contained in the capillaries, is represented, while an analysis of a portion of hepatized lung represents very nearly the composition of the adventitious matter upon the effusion of which the solidification depends, for the proportion of lung tissue compared to that of the inflammatory products is so small, that its presence may be almost entirely disregarded-the analysis of healthy lung will represent the chemical composition of a considerable part of one lobe, but that of the inflamed lung represents the composition of only a very small part of the portion of lung which has undergone hepatization.

Where inflammation has involved a considerable portion or the whole of one lung, the quantity of salts per cent., and the amount of chloride of sodium present, will be found to be less than if only a small portion of the lung had been affected, in consequence of the salt being distributed over a greater amount of space in the former, than in the latter case.

The analyses of both lungs of Flynn (Case 1x,) will be found at pages 357,358 , to which the reader is referred for the results.

The specimens of lung referred to in the following analyses, were taken from patients whose secretions were not subjected to examination during life.

The lung, of which the following is an analysis, was apparently healthy. It was of a pale colour, with little blood in the vessels, and the air-cells were well filled with air. The lung was taken from a patient, æt. 49, whodied in King's College 
Hospital from the exhaustion consequent upon contracted pylorus, which depended on the thickening and contraction produced by the presence of two large ulcers situated in the pyloric orifice. This man suffered much from frequently vomiting a large quantity of the characteristic fermented vomit containing sarcinse.

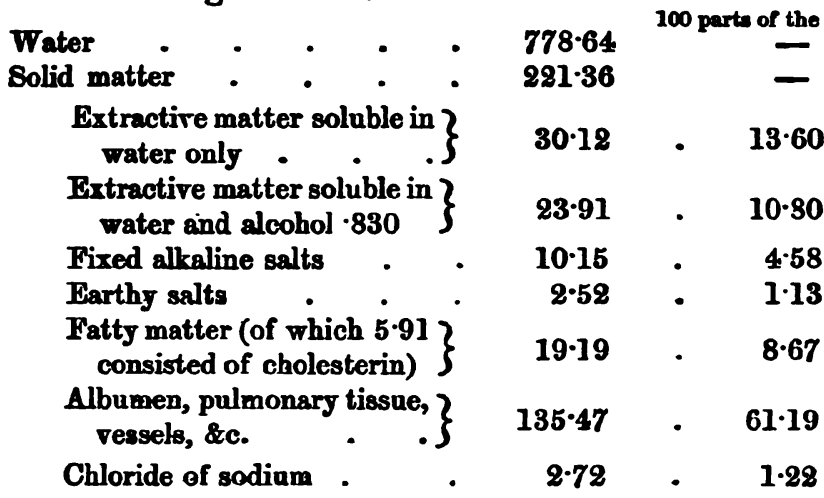

The following is an analysis of a portion of lung in the state of red hepatization, which was-taken from a man, æt. 27, who died in the hospital the day after his admission. No history of his case was recorded. The lower lobe of the left lung was hepatized in every part, and small portions that were cut off and thrown into water immediately sank.

Water . . . . . . . $842 \cdot 70$

Solid matter $\quad . \quad+\quad . \quad \therefore \quad 157 \cdot 30$

100 parts of the solid matter.

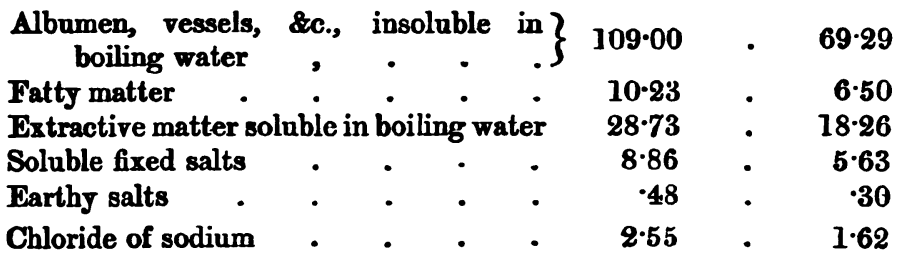

The lung, of which the following is an analysis, was taken from a patient of the name of Jane Roberts, at. 34, who died in the hospital suddenly in consequence of rupture of 
an aortic aneurism into one of the bronchial tubes. The patient had been admitted in consequence of effusion into the cavity of the pleura of the left side. The left lung was about half the natural size, of a grey colour, and quite solid. It appeared to be in a state of grey hepatization rather than carnified.

941.6 grains were submitted to analysis, and the results obtained calculated to 1000 grains.

Water

Solid matter

100 parts of the solid matter.

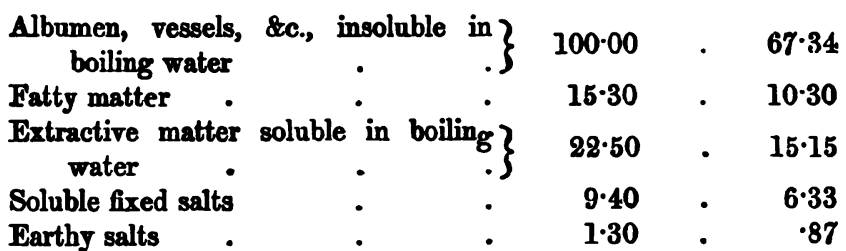

The soluble fixed salts contained-

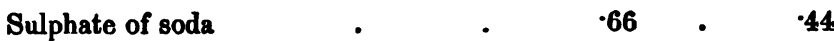

$\begin{array}{llllll}\text { Chloride of sodium } & \text { - } & - & 5 \cdot 38 & \text { - } & 3 \cdot 62\end{array}$

TABLE I.

Showing the quantities of the principal Constituents in 100 parts of solid matter of the Urine in the different cases.

\begin{tabular}{|c|c|c|c|c|c|c|c|c|c|c|c|c|}
\hline \multirow{6}{*}{$\begin{array}{r}\text { No. of Case } \\
\text { specific gravity .. } \\
\text { Solid matter .... } \\
\text { Organic matter ... } \\
\text { Fixed salts ..... } \\
\text { Chloride of sodium }\end{array}$} & . & .. & 1. & & & 2. & \multicolumn{3}{|c|}{3.} & \multicolumn{3}{|c|}{5.} \\
\hline & 1017 & 1013 & 1016 & 1022 & 1016 & - & 1017 & 1015 & 1020 & 1025 & 1026 & 1020 \\
\hline & 00 & $100 \cdot 00$ & 00 & $100 \cdot 00$ & $100 \cdot 00$ & 100.00 & $100 \cdot 00$ & 100.00 & $100 \cdot 00$ & $100 \cdot 00$ & $100 \cdot 00$ & $100 \cdot 00$ \\
\hline & $92-82$ & - & $97 \cdot 05$ & $93 \cdot 6$ & $.73 \cdot 61$ & 89.55 & 03.23 & $97 \cdot 92$ & $92 \cdot 91$ & $93 \cdot 48$ & $85 \cdot 82$ & $81 \cdot 6$ \\
\hline & $7 \cdot 18$ & - & $2 \cdot 95$ & $6 \cdot 4$ & $26 \cdot 39$ & $10 \cdot 45$ & $6 \cdot 77$ & $2 \cdot 28$ & $7 \cdot 09$ & 6.52 & $14 \cdot 18$ & $18 \cdot 3$ \\
\hline & o & |traces| & 0 & 0 & $|14: 43|$ & traces & 0 & O & 0 & 0 & traces & 0 \\
\hline No of $\mathrm{C}$ & lase & $\ldots \ldots$ & 6. & & 7 & $\dot{0}$ & & 8. & & 9. & & \\
\hline Specific & ty & 1022 & 1022 & 1026 & 1018 & 1020 & 1015 & 51022 & 1028 & $2: 1023$ & 1018 & \\
\hline Solid matter & & $100 \cdot 00$ & 100.00 & $100 \cdot 00$ & 00 & $100 \cdot 00$ & $100 \cdot 00$ & $100 \cdot 00$ & 100.00 & 0100.00 & $100 \cdot 00$ & \\
\hline Organic matt & ex .. & $88 \cdot 27$ & $94 \cdot 30$ & 89.00 & 93.05 & $79 \cdot 08$ & $92 \cdot 73$ & $84 \cdot 34$ & $84 \cdot 65$ & 590.04 & 86.05 & \\
\hline Fixed salts & $\cdots \cdots$ & 1173 & 5.70 & 11.00 & 6.95 & $20 \cdot 92$ & $7 \cdot 27$ & $15 \cdot 56$ & $15 \cdot 35$ & 59.96 & 13.95 & \\
\hline thlo & dium & 0 & 0 & 0 & traces & 6.51 & $\begin{array}{c}\text { not } \\
\text { esti- } \\
\text { mated }\end{array}$ & traces & traces & 8 & 0 & \\
\hline
\end{tabular}




\section{TABLE II.}

Showing the quantities of the inorganic Constituents in 100 parts of solid matter in the opecimens of Sputa.

\begin{tabular}{|c|c|c|c|c|c|c|c|}
\hline \multirow{2}{*}{$\begin{array}{l}\text { No. of Case } \\
\text { Specific gravity : } \\
\text { Solid matter } \\
\text { Fixed salts } \\
\text { Chloride of sodium }\end{array}$} & & \multirow{2}{*}{ 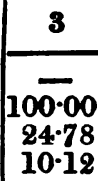 } & \multirow{2}{*}{\begin{tabular}{|c}
\multicolumn{7}{|c}{} \\
$100 \cdot 00$ \\
$32 \cdot 86$ \\
$18 \cdot 11$
\end{tabular}} & \multirow{2}{*}{ 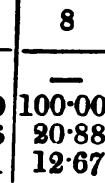 } & \multicolumn{3}{|c|}{9} \\
\hline & & & & & $\begin{array}{r}1014 \\
100 \cdot 00 \\
14.37 \\
8.68\end{array}$ & $\mid \begin{array}{r}1028 \\
100 \cdot 00 \\
8 \cdot 44 \\
4 \cdot 34\end{array}$ & $\begin{array}{r}1032 \cdot 8 \\
100 \cdot 00 \\
7 \cdot 32 \\
8.86\end{array}$ \\
\hline
\end{tabular}

\section{TABLE III.}

Showing the quantities of the principal Constituents in 100 parts of solid matter of the different specimens of Lung.

\begin{tabular}{|c|c|c|c|c|c|}
\hline & $\begin{array}{l}\text { Healthy } \\
\text { Lung. }\end{array}$ & $\begin{array}{l}\text { Congested } \\
\text { Lung. (9.) }\end{array}$ & $\begin{array}{l}\text { Hepatized } \\
\text { Lung. (9.) }\end{array}$ & $\begin{array}{c}\text { Grey } \\
\text { Hepatiza- } \\
\text { tion. }\end{array}$ & $\begin{array}{c}\text { Red } \\
\text { Hepatiza- } \\
\text { tion. }\end{array}$ \\
\hline Solid matter & $100 \cdot 00$ & $100 \cdot 00$ & $100 \cdot 00$ & $100 \cdot 00$ & $100 \cdot 00$ \\
\hline $\begin{array}{l}\text { Extractive matter, solu- } \\
\text { ble in water only }\end{array}$ & $13 \cdot 60$ & $7 \cdot 15$ & $21 \cdot 27.7$ & & \\
\hline $\left.\begin{array}{l}\text { Extractive matter, solu- } \\
\text { ble in water and } \\
\text { alcohol } \cdot \mathbf{8 3 0}\end{array}\right\}$ & $10 \cdot 80$ & $8 \cdot 65$ & 26 & $15 \cdot 15$ & $18-26$ \\
\hline $\begin{array}{l}\text { Fixed alkaline salts } \\
\text { Earthy salts : } \\
\text { Fatty matter : }\end{array}$ & $\begin{array}{l}4 \cdot 58 \\
1 \cdot 13 \\
8 \cdot 67\end{array}$ & $\begin{array}{l}4 \cdot 46 \\
1 \cdot 61 \\
8 \cdot 11\end{array}$ & $\begin{array}{r}4 \cdot 22 \\
\cdot 51 \\
10 \cdot 29\end{array}$ & $\begin{array}{r}6 \cdot 33 \\
\cdot 87 \\
10 \cdot 30\end{array}$ & $\begin{array}{r}5 \cdot 63 \\
\cdot 30 \\
6 \cdot 50\end{array}$ \\
\hline 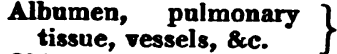 & $61 \cdot 19$ & 70.01 & $36 \cdot 80$ & $67 \cdot 34$ & $69 \cdot 29$ \\
\hline Chloride of sodium & $1 \cdot 22$ & .85 & $1 \cdot 41$ & $3 \cdot 62$ & $1 \cdot 62$ \\
\hline
\end{tabular}

The most important points which I have endeavoured to establish in this communication, are as follow :

1. That in pneumonia there is a total absence of chloride of sodium from the urine, at or about the period of hepatization of the lung.

2. That soon after resolution of the inflammation, the chloride becomes restored to the urine, and often in considerable quantity. ${ }^{1}$

3. That at this period the serum of the blood is found to contain a greater amount of chloride than in health.

4. That the presence of chloride of sodium in the urine

- The first and second conclusions are confirmatory of Dr. Redtenbacher's observations. 
may be taken as evidence of the existence of a greater quantity of the salt in the blood, than is required for the wants of the system generally, or at least of an amount sufficient for that purpose; and that the absence of the salt from the urine indicates that the circulating fluid contains less than the normal quantity.

5. That the sputa in pneumonia contain a greater quantity of fixed chloride than healthy pulmonary mucus, if there be not much less than a normal amount in the blood, although there be a complete absence of the salt from the urine. In all cases, however, there is found in the sputa a quantity many times greater than exists in an equal amount of blood at the same period of the disease. The absolute amount present is subject to variation at different periods of the disease, and in different cases.

6. That in Case Ix, as the disease approached a fatal termination, the proportion of chloride present in the sputa underwent a decrease, while the amount of solid matter, and especially the extractive matters, increased in quantity. At the same time the sputa became acid, and in the matters expectorated within the last few hours of the patient's life, there existed evidence of the presence of a large quantity of grape sugar, but in that obtained on the day previous to his death none could be detected.

7. That there is reason to believe, that the absence of the chloride of sodium from the urine during the stage of hepatization, depends upon a determination of this salt to the inflamed lung, and that when resolution occurs, this force of attraction ceases, and whatever salt has been retained in the lung is reabsorbed, and appears in the urine in the usual way. 